\title{
Hatay ilindeki göletlerin hazne hacimlerinin coğrafi bilgi sistemleri ile belirlenmesi
}

\section{Determining reservoir water volume of ponds in Hatay province using Geographic Information Systems}

\author{
Ayşe Nisa TOPER ${ }^{1}$ iD , Ahmet íRVEM ${ }^{2}$ \\ ${ }^{1}$ Hatay Metropolitan Municipality, Department of Environmental Protection and Control, Antakya-Hatay, Turkey. \\ ${ }^{2}$ Hatay Mustafa Kemal University, Faculty of Agriculture, Department of Biosystem Engineering, Antakya-Hatay, Turkey.
}

MAKALE BILGISI / ARTICLE INFO

Makale tarihçesi / Article history:

DOI: $10.37908 /$ mkutbd.928674

Geliş tarihi /Received:27.04.2021

Kabul tarihi/Accepted:30.06.2021

\section{Keywords:}

Pond, GIS, volume calculation, digital elevation map, Hatay.

Corresponding author: Ahmet IRVEM

$\triangle$ : airvem@mku.edu.tr

\section{ÖZET / A BSTRACT}

Atıf / Citation: Toper AN, irvem A (2021) Hatay ilindeki göletlerin hazne hacimlerinin coğrafi bilgi sistemleri ile belirlenmesi. MKU. Tar. Bil. Derg. 26(2) : 452-460. DOI: 10.37908/mkutbd.928674 


\section{GíRiş}

Baraj ve göletler, özellikle yarı-kurak iklim bölgelerinde, kaynak sularını ve kış döneminde yağış sularını depolayan ve depolanan suyun özellikle yaz dönemlerinde başta tarımsal sulama ve içme suyu olmak üzere çeşitli amaçlar için kullanıımasını sağlayan mühendislik yapılarıdır. Barajların ve göletlerin hazne hacimleri ve depolanan suyun kapladığı alanı tahmin için GIS ile entegre uydu görüntülerinin kullanılmasının, daha az zaman ve maliyetlerle uygulanabilir olduğunu belirten çok sayıda çalışma yapılmıştır (Tsihrintzis ve ark., 1996; Gupta ve ark., 1997; Liebe ve ark.,, 2005; Sawunyama ve ark., 2006; İrvem, 2011; Cvar, 2014; Zhang ve ark., 2014). Göletler hacimsel olarak barajlara göre çok daha küçük su depolayan yapılardır. Bu nedenle gölet yapımına uygun yerler, barajlara göre daha fazladır. Ekonomik açıdan göletlerin inşası daha az yatırım gerektirmekte ve mühendislik hesaplamaları daha basit olmaktadır. Internet ortamından topografik verilere kolay ulaşım nedeniyle, su depolama yapılarının projelenmesinde Sayısal Yükseklik Modelleri (SYM) çok sayıda araştırmacı tarafından farklı amaçlar için kullanılmıştır (Nisar Ahamed ve ark., 2002; Jha ve ark., 2006; Mialhe ve ark., 2008; Chowdary ve ark., 2009; Mwenge ve ark., 2009; Pistrika, 2010; Gwenzi and Nyamadzawo, 2014).

Türkiye'de son yıllarda devletin teşviki ile çok sayıda gölet yapılmış ve yapılmaktadır. Hatay ilinde de, il Özel İdaresi ve Hatay Büyükşehir Belediyesi Park ve Bahçeler Daire Başkanlığı tarafından son yıllarda çok sayıda gölet yapılmış ve işletmeye açılmıştır.

Bir su depolama yapısının hazne kapasitesi, topografyaya bağlı olarak gölet gövde yüksekliğine göre, CBS ile önceden belirlenebilmektedir. Taşkın ve İrvem (2014) yapmış oldukları çalışmalarında CBS kullanarak, Hatay Mustafa Kemal Üniversitesi çevresinde uygun gölet yerlerini ve hazne hacimlerini belirlemişlerdir. Çalışma sonucunda 13 adet gölet yeri tespit edilerek bu yerlerin uygunlukları bazı kriterler dikkate alınarak değerlendirilmiştir. İrvem (2020) Hatay Büyük Karaçay barajının hacmini tahmin etmede farklı piksellere sahip

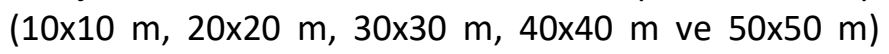
topografik haritaları kullanmıştır. Piksel boyutunun hacim tahmininde etkinliğinin araştırıldığı bu çalışmada, 10x10 metre piksele sahip topografik harita kullanılarak hesaplanan baraj hazne hacminin en doğru tahmini verdiği görülmüştür.

Uydu görüntüleri ve sayısal topografik haritalar kullanılarak CBS ile gölet hacimlerinin önceden tespiti, göletlerin fizibilite çalışmalarında karar vericiler için önemli bir avantajdır. Bir göletin yapımının, ekonomik açıdan uygun olup olmadığı bu çalışmalar sonucunda hızlı bir şekilde belirlenebilir. Bu bakımdan, göletlerin su depolama hacimlerinin CBS kullanılarak kolayca ve kısa sürede önceden hesaplanabilmesi yanında, CBS ile elde edilen sonuçların doğruluğu da mutlaka araştırılmalıdır. CBS yardımıyla tahmin edilen hazne hacimleri ile göletlerin gerçek hacim değerleri kıyaslanarak doğrulukları kontrol edilebilir. Ülkemizde bu konuda yapılmış çalışmalar yok denecek kadar azdır. Bu çalışma ile Hatay ilinin farklı bölgelerinde yapılmış ve işletmeye açılmıs olan 10 göletin depolama hacimleri, sayısal yükseklik haritası kullanılarak CBS ile tahmin edilmiş, tahmin sonuçları arazide yapılan ölçümler sonucunda elde edilen gerçek depolama hacimleri ile kıyaslayarak doğrulukları istatistiksel yöntemlerle değerlendirilmiştir.

\section{MATERYAL ve YÖNTEM}

\section{Çalışma alanı}

Bu çalışma, Hatay ilinde II Özel İdaresi ve Hatay Büyükşehir Belediyesi, Park Bahçe ve Yeşil Alanlar Daire Başkanlığı ve Devlet Su İşleri (DSi) tarafından sulama amaçlı, 8'i toprak dolgu, ikisi kaya-toprak dolgu gövdeli olarak projelenmiş ve işletmeye açılmış 10 gölette yürütülmüştür. Belende Güzelyayla, Antakya'da Karlısu, Samandağ'da Karamanlı ve Yayladağ'da bulunan Dağdüzü, Yoncakaya, Yalaz, 23 Temmuz, Hisarcık, Kızılçat ve Pulluyazı göletleridir. Çalışmanın yürütüldüğü göletlerin konumları Şekil 1'de verilmiştir.

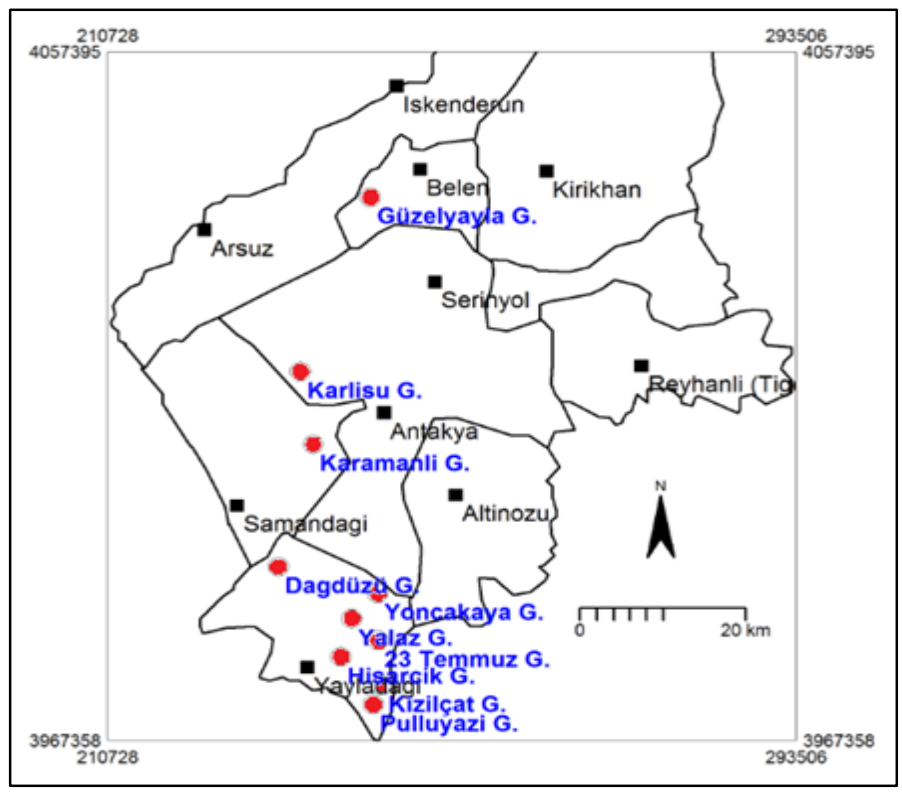

Şekil 1. Çalışma alanı ve göletlerin konumları Figure 1. Study area and locations of ponds 


\section{Sayısal yükseklik modelinin (SYM) oluşturulması}

Bu çalışma için gerekli sayısal yükseklik modeli, hücre tabanlı 10x10 metre çözünürlüğe sahip sayısal topografik harita bilgilerinin ILWIS $3.6^{\prime}$ da kullanılması ile oluşturulmuştur. Bu model, $\mathrm{CBS}^{\prime}$ de arazi yüzeyinin üç boyutlu görselleştirilmesinde, arazide herhangi bir noktada yüksekliğin bulunmasında, arazi yüzeyinin eğim ve bakısının bulunmasında, mevcut su akış yollarının haritalanmasında kullanılmıştır.

\section{Su yönleri ve drenaj ağının belirlenmesi}

Gölet yerinin koordinatları dikkate alınarak yerler belirlenmiştir. Gövdenin tam olarak belirlenmesinde, çalışma alanı su akış yollarının diğer bir ifade ile havza drenaj ağının bilinmesi gerekmektedir. Bu amaçla, sayısal yükseklik modeli kullanılarak su akış yönleri, su birikim haritasını veren iki harita oluşturulmuştur. Bu iki haritadan, su akış yönleri ve sayısal yükseklik haritası birlikte kullanılarak, çalışma alanı için su akış yollarını veren drenaj ağı haritası çıkarılmıştır.

\section{Sanal barajların oluşturulması}

Drenaj ağı bir havzada su kollarını gösteren bir haritadır. Bu haritada, gölet koordinat bilgileri de kullanılarak su kolu üzerinde sanal gölet gövdesinin yeri belirlenmiştir. Bu yerlerde, göletlerin gerçek kret yüksekliklerine göre sanal olarak gölet gövdeleri oluşturulmuştur.

\section{Göletlerin depolanabilir su hacmi hesaplamaları}

Oluşturulan sanal gölet gövdeleri, gövde yüksekliklerine göre depolanabilir su hacimleri ILWIS yazılımında mantıksal komutlar ve eşitlikler ile tahmin edilmiştir.

\section{Göletlerin hacim-kot grafiklerinin geliştirilmesi}

Sanal göletler için maksimum su kotuna göre brüt depolanabilir su hacimleri hesaplanmıştır. Bu hesaplama işlemlerinde, ILWIS yazılımında Cross komutu kullanılarak FLOODED ve DEMSMALL harita verilerinden, kot ve alan bilgisini içeren bir tablo oluşturulmuştur. Oluşturulan tablodaki, hacim değerleri ve kot bilgilerinden, ILWIS grafik menüsü yardımıyla her bir gölet için depolanabilir su hacmi-kot grafikleri çıkarılmıştır.

\section{Sonuçların değerlendirilmesi}

Tahmin edilen gölet hacimleri ile hesaplanan gerçek hacimleri kıyaslamak için üç istatistiki ölçüt kullanılmıştır. Bunlar doğrusal ilişki derecesini belirleme katsayısı $\left(R^{2}\right)$, verilere en iyi uyan çizgi etrafında o verilerin ne kadar yoğun olduğunu gösteren Hata Kare Ortalamasının Karekökü (RMSE), veri setleri tarafından tahmin edilen su depolama miktarı ile gerçek depolanan su miktarları arasındaki ortalama farkı gösteren Bias'tır (Irvem ve Ozbuldu, 2019).

Tahmin edilen su depolama miktarı ile gerçek depolanan su miktarları arasındaki doğrusal ilişki derecesini belirleme katsayısı eşitlik 1'deki denklem ile hesaplanmıştır;

$R^{2}=\left(\frac{n \sum\left(O_{i} M_{i}\right)-\left(\sum o_{i}\right)\left(\sum M_{i}\right)}{\sqrt{\left(n\left(\sum o_{i}^{2}\right)-\left(\sum o_{i}\right)^{2}\right)\left(n\left(M_{i}^{2}\right)-\left(\sum M_{i}\right)^{2}\right)}}\right)^{2}$

$$
\begin{array}{ll} 
& \text { Burada; } \\
O_{i} & \text { : Gözlem Verileri } \\
M_{i} & \text { : Model Tahmin Verileri } \\
n & \text { : Veri sayısı }
\end{array}
$$

Tahmin edilen su depolama miktarı ile gerçek depolanan su miktarları verilerinin arasındaki RMSE değeri ise eşitlik 2'den hesaplanmıştır; RMSE'nin değeri her zaman pozitif olmalıdır ve sıfıra yakın olması istenir. Değer ne kadar küçük olursa, modelin performansının o kadar iyi olduğunu belirtmektedir. RMSE, model çıktıları ve gözlemlenen değerler arasındaki sapmanın karşılaştırılmasını sağlayarak, korelasyonların kısa süreli performansı hakkında bilgi vermektedir.

$R M S E=\sqrt{\frac{\sum(O-M)^{2}}{n}}$

Burada;

$O \quad$ : Gözlem Verileri

$M$ : Model Tahmin Verileri

$n \quad$ : Veri sayısı

Model tahmin değerlerinin gözlenen değerlerden negatif ya da pozitif yönde ne kadar uzak olduğunu belirlemek için kullanılmaktadır. Pozitif değerler gözlenen değerlerin tahmin değerlerinden büyük olduğunu gösterirken negatif değerler tam tersi durumu ifade eder. PBias değeri ise eşitlik 3 kullanılarak hesaplanmıştır;

$$
\text { PBIAS }=\left\lfloor\frac{\sum_{i=1}^{n}\left(O_{i}-M_{i}\right)}{\sum_{i=1}^{n} o_{i}}\right\rfloor \times 100
$$

Burada;

$\begin{array}{ll}O_{i} & : \text { Gözlem Verileri } \\ M_{\tilde{i}} & : \text { Model Tahmin Verileri } \\ n & : \text { Veri sayısı }\end{array}$


Nash-Sutcliffe verimliliği (NSE), modelin tahmin kabiliyetini temsil eden gösterge değerini verir. Aldığı değerler $-\infty$ ile 1 arasındadır. Aldığı değerin 0-1 arasında olması istenen durumdur ve 1 'e yaklaştıkça modelin iyi bir tahmin sonucu verdiğini gösterir. NashSutcliffe verimliliği (NSE) eşitlik 4 kullanılarak hesaplanmıştır.

$N S E=1-\frac{\sum_{i=1}^{n}\left(O_{i}-M_{i}\right)^{2}}{\sum_{i=1}^{n}\left(O_{i}-\bar{O}\right)^{2}}$

Burada;

$O_{i} \quad$ : Gözlem verileri

$M_{i} \quad$ : Model tahmin verileri

$\bar{O} \quad$ : Gözlem verilerinin ortalaması

$n \quad$ : Veri sayısı

NSE ve PBias için sonuçları sınıflandırarak değerlendirme tablosu Çizelge $1^{\prime}$ de verilmiştir (Moriasi ve ark., 2007).

Çizelge 1. NSE and PBias sonuçları değerlendirme Table 1. Performance evaluation for NSE and PBias results

\begin{tabular}{lcc}
\hline Derece & NSE & PBias \\
\hline Çok Iyyi & $0.75<$ NSE $<1.00$ & Bias $< \pm 10$ \\
İyi & $0.65<$ NSE $<0.75$ & $\pm 10<$ Bias $< \pm 15$ \\
Yeterli & $0.50<$ NSE $<0.65$ & $\pm 15<$ Bias $< \pm 25$ \\
Yetersiz & NSE $<0.50$ & Bias $> \pm 25$ \\
\hline
\end{tabular}

\section{BULGULAR ve TARTIŞMA}

Bu çalışmada, Hatay ilinde bulunan 10 gölet için sanal gölet gövdeleri oluşturularak ve hazne depolama hacimleri tahmin edilmiştir. Çalışmadaki tüm göletlere ait özellikler (Toper, 2020)'de detaylı olarak verilmektedir. Burada örnek olması amacıyla sadece Yayladağ'da bulunan Pulluyazı göletine yönelik yapılan çalışmalar özetlenmiştir.

\section{Çalışma alanı sayısal yükseklik haritası}

Çalışma alanı olan Hatay ilinin sayısal yükseklik haritası topografik veriler kullanılarak ILWIS yazılımında oluşturulmuştur. Oluşturulan Hatay ili SYH Şekil 2'de verilmiştir.

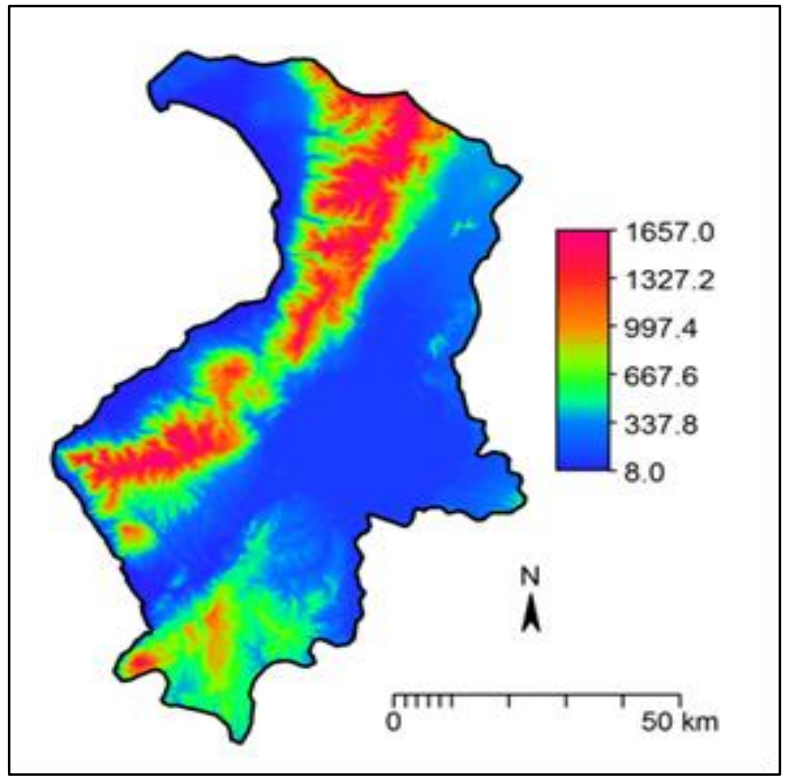

Şekil 2. Sayısal yükseklik haritası Figure 2. Digital elevation map

\section{Yayladağı Pulluyazı Göleti hacim hesaplama sonuçları} Yayladağı ilçesi sınırları içerisinde bulunan ve 2009 yılında inşaatı tamamlanan Pulluyazı göleti bu çalışmada örnek olarak verilmiştir. Hatay ili için oluşturulan SYH kullanılarak, Pulluyazı göletinin 10×10 metre hücre boyutuna sahip sayısal yükseklik haritası geliştirilmiştir. Geliştirilen sayısal yükseklik haritası Şekil 3' de verilmiştir.

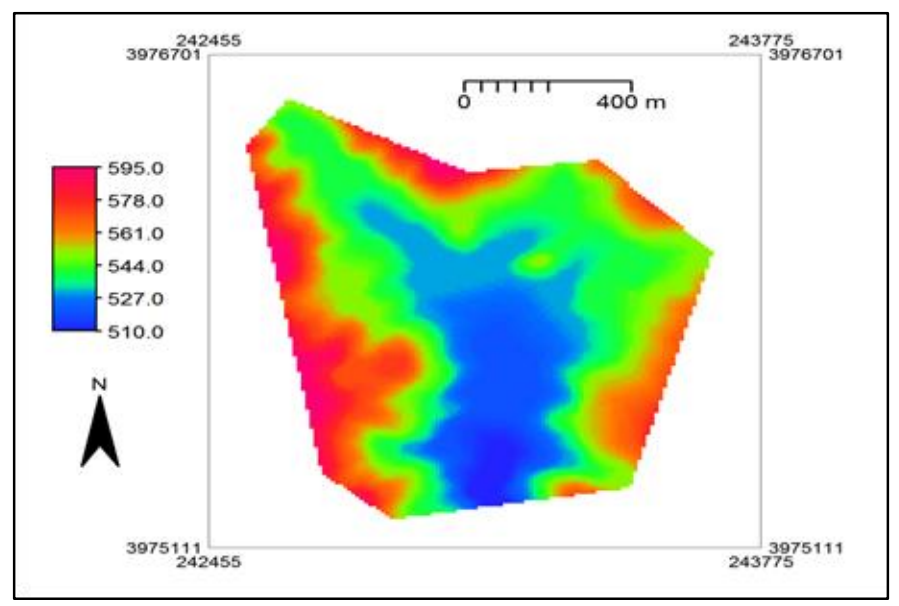

Şekil 3. Yayladağı Pulluyazı Göleti sayısal yükseklik haritası

Figure 3. Digital elevation map fort he Pulluyazı pond 
Sayısal Yükseklik Haritası üzerinde sanal gölet gövdesi göletin brüt depolama hacim kotu dikkate alınarak oluşturulmuştur. Göletin bulunduğu bölgede maksimum yükselti 595 metre, minimum yükselti 510 metredir. Kavur Deresi üzerinde bulunan göletin, talveg kotu 506.00 metre, maksimum su kotu 528.18 metre, kret kotu 530.18 metre, kret uzunluğu 181 metre ve maksimum gövde yüksekliği 24.18 metredir. Maksimum su kotunda göletin brüt depolama hacmi 1975000 $\mathrm{m}^{3 \prime}$ tür. Gölet için oluşturulan sanal baraj gövdesi Şekil 4'de, uydu görüntüsü ise Şekil 5'de verilmiştir.

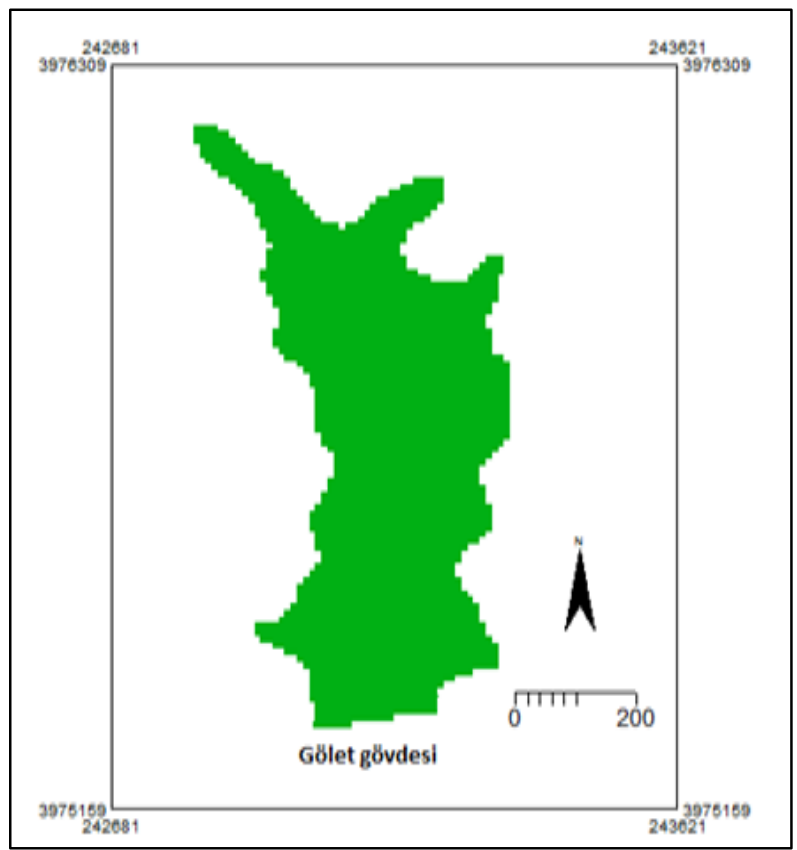

Şekil 4. Sanal gölet gövdesi ve su yüzeyi alanı Figure 4. Virtua pond crest and water surface area

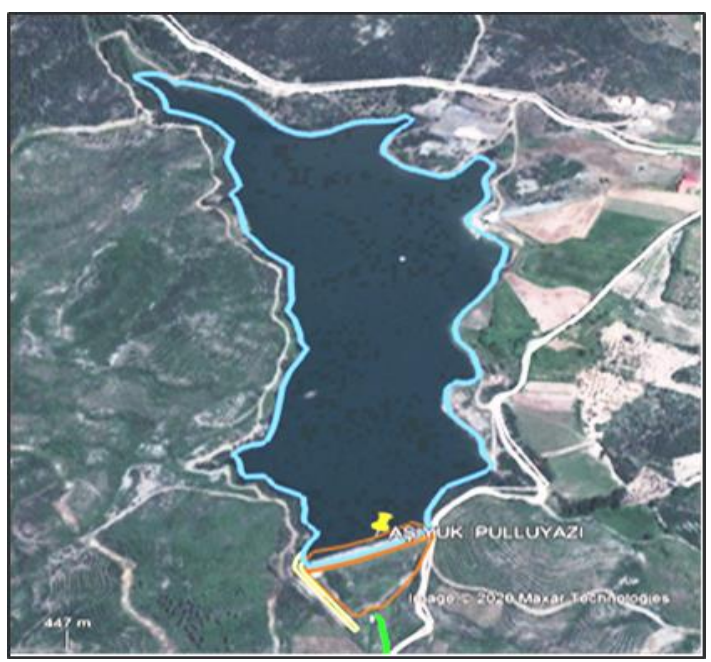

Şekil 5.Göletin uydu görüntüsü

Figure 5. Satellite image of pond

Sanal gölet gövdesi için maksimum su kotu $531 \mathrm{~m}$ alınmıştır. Buna göre göletin brüt depolama hacmi 1
$856100 \mathrm{~m}^{3}$ olarak hesaplanmıştır. Hesaplama ile ilgili sonuçlar Şekil 6'da, programın grafik menüsünden elde edilen kot hacim grafiği ise Şekil 7'de verilmiştir.

\begin{tabular}{|c|c|c|c|c|c|c|c|}
\hline \multicolumn{8}{|c|}{ (10) Dependent Table "volume" - TableCross(flood.n } \\
\hline \multicolumn{8}{|c|}{ File Edit Columns Records View Help } \\
\hline \multicolumn{8}{|c|}{ 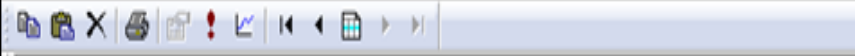 } \\
\hline (1) & flood & demsmall & NPix & Area & depth & vol & cumvo1 \\
\hline True * 510.0 & True & 510.0 & 133 & 13300 & 21.0 & 279300.0 & 279300.0 \\
\hline True * 511.0 & True & 511.0 & 34 & 3400 & 20.0 & 68000.0 & 347300.0 \\
\hline True * 512.0 & True & 512.0 & 24 & 2400 & 19.0 & 45600.0 & 392900.0 \\
\hline True * 513.0 & Irue & 513.0 & 29 & 2900 & 18.0 & $\$ 2200.0$ & 445100.0 \\
\hline True * 514.0 & True & $\$ 14.0$ & 33 & 3300 & 17.0 & $\$ 6100.0$ & $\$ 01200.0$ \\
\hline True * 515.0 & True & 515.0 & 30 & 3000 & 16.0 & 48000.0 & $\$ 49200.0$ \\
\hline True * 516.0 & True & 516.0 & 37 & 3700 & 15.0 & 55500.0 & 604700.0 \\
\hline True * 517.0 & True & 517.0 & 36 & 3600 & 14.0 & 50400.0 & 655100.0 \\
\hline True * 518.0 & True & 518.0 & 39 & 3900 & 13.0 & 50700.0 & 705800.0 \\
\hline True * 519.0 & True & 519.0 & 41 & 4100 & 12.0 & 49200.0 & 755000.0 \\
\hline True * 520.0 & True & 520.0 & 443 & 44300 & 11.0 & 487300.0 & 1242300.0 \\
\hline True * 521.0 & True & 521.0 & 99 & 9900 & 10.0 & 99000.0 & 1341300.0 \\
\hline True * 522.0 & True & 522.0 & 76 & 7600 & 9.0 & 68400.0 & 1409700.0 \\
\hline True * 523.0 & True & 523.0 & 97 & 9700 & 8.0 & 77600.0 & 1487300.0 \\
\hline True * 524.0 & True & 524.0 & 102 & 10200 & 7.0 & 71400.0 & 1558700.0 \\
\hline True * 525.0 & True & 525.0 & 105 & 10500 & 6.0 & 63000.0 & 1621700.0 \\
\hline True * 526.0 & True & 526.0 & 112 & 11200 & 5.0 & $\$ 6000.0$ & 1677700.0 \\
\hline True * $\$ 27.0$ & True & $\$ 27.0$ & 124 & 12400 & 4.0 & 49600.0 & 1727300.0 \\
\hline True * 528.0 & True & 528.0 & 136 & 13600 & 3.0 & 40800.0 & 1768100.0 \\
\hline True * 529.0 & True & 529.0 & 130 & 13000 & 2.0 & 26000.0 & 1794100.0 \\
\hline True * 530.0 & True & 530.0 & 620 & 62000 & 1.0 & 62000.0 & 1856100.0 \\
\hline True * 531.0 & True & 531.0 & 204 & 20400 & 0.0 & 0.0 & 1856100.0 \\
\hline Min & True & 510.0 & 24 & 2400 & 0.0 & 0.0 & 279300.0 \\
\hline $\operatorname{Max}$ & True & 531.0 & 620 & 62000 & 21.0 & 487300.0 & 1856100.0 \\
\hline Avg & & 520.5 & 122 & 12200 & 10.5 & 84368.2 & 1117090.9 \\
\hline$S t D$ & & 6.5 & 144 & 14354 & 6.5 & 103673.9 & $\$ 83417.6$ \\
\hline Sum & & 11451.0 & 2684 & 268400 & 231.0 & 1856100.0 & 24576000.0 \\
\hline
\end{tabular}

Şekil 6. Hacim hesaplama sonuçları

Figure 6. Results of volume calculations

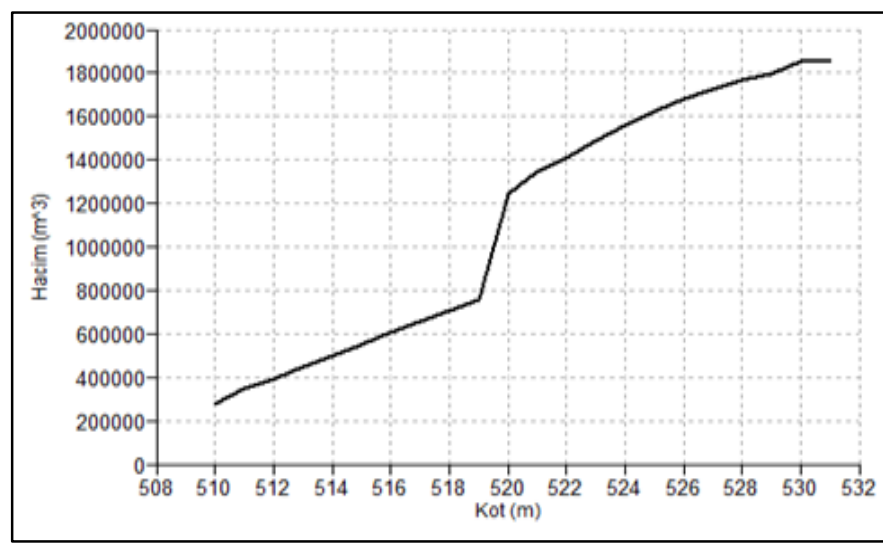

Şekil 7. Gölet hacim-kot grafiği

Figure 7. Volume-height graph for pond

Yapılan hacim hesaplamaları sonucunda, tahmin edilen hacmin, gerçekteki hacimden yaklaşık $119000 \mathrm{~m}^{3}$ daha az olduğu görülmüştür. 


\section{Sonuçların kıyaslanması}

CBS ile sayısal yükseklik haritası kullanılarak tahmin edilen gölet hacimleri ile arazi ölçmeleri ile hesaplanan gölet hacimleri Çizelge 2'de yapılan istatistiksel analizlerin sonuçları Çizelge $3^{\prime}$ de verilmiştir.

Çizelge 2. Ölçülen ve tahmin edilen gölet hacimleri Table 2. Measured and estimated pond volumes

\begin{tabular}{lcc}
\hline $\begin{array}{l}\text { Gölet ismi } \\
\text { (Pond name) }\end{array}$ & $\begin{array}{r}\text { Ölçülen hacim } \\
\left(\mathrm{hm}^{3}\right)\end{array}$ & $\begin{array}{r}\text { Tahmin edilen hacim } \\
\left(\mathrm{hm}^{3}\right)\end{array}$ \\
(Measured volume) & (Estimated Volume) \\
\hline 23 Temmuz & 1.353 & 1.330 \\
Karlısu & 0.589 & 0.620 \\
Pulluyazı & 1.975 & 1.856 \\
Dağdüzü & 0.337 & 0.337 \\
Kızılçat & 0.241 & 0.235 \\
Yoncakaya & 0.101 & 0.142 \\
Güzelyayla & 0.283 & 0.389 \\
Hisarcık & 0.231 & 0.332 \\
Yalaz & 0.022 & 0.019 \\
Karamanlı & 2.110 & 3.857 \\
\hline
\end{tabular}

Çizelge 3. İstatistiksel sonuçlar

Table 3. Statistical results

\begin{tabular}{lcccll}
\hline & $\mathrm{R}^{2}$ & Pbias & RMSE & \multicolumn{1}{c}{ NS } & Sonuç \\
\hline $\begin{array}{l}\text { Karamanlı } \\
\text { Göleti ile }\end{array}$ & 0.84 & $\begin{array}{l}-25.0837 \\
\text { Pbias }>25\end{array}$ & 0.5560 & $\begin{array}{l}0.420579 \\
(<0.50)\end{array}$ & $\begin{array}{l}\text { Tahmin } \\
\text { kötü }\end{array}$ \\
$\begin{array}{l}\text { Karamanlı } \\
\begin{array}{l}\text { Göleti } \\
\text { olmadan }\end{array}\end{array}$ & 0.99 & $\begin{array}{l}-2.32187 \\
\text { Pbias }<10\end{array}$ & 0.0656 & $\begin{array}{l}0.988122 \\
(>0.75)\end{array}$ & $\begin{array}{l}\text { Tahmin } \\
\text { çok iyi }\end{array}$ \\
\hline
\end{tabular}

Bu sonuçlara göre, tüm göletler için ölçülen ve tahmin edilen hacim değerleri Şekil 8'de verilmiştir.

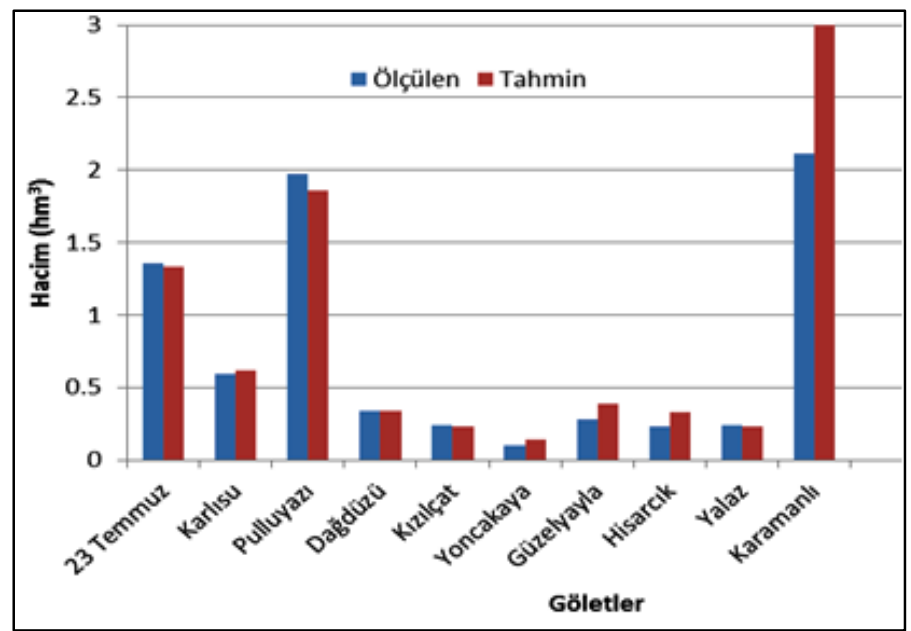

Şekil 8. Ölçülen ve tahmin edilen hacim değerleri

Figure 8. Measured and estimated volumes

Tüm göletler için ölçülen ve tahmin edilen hacim değerlerin için belirleme katsayısı $R^{2}=0.84$ çıkmıştır.
Tüm göletler içerisinde Karamanlı Göleti için hesaplanan hacim değeri $3.857 \mathrm{hm}^{3}$, ölçülen $2.110 \mathrm{hm}^{3}$ değerinin çok üstünde çıkmıştır. Ölçülen değerde bir hata olabileceği ya da zamanla gölet haznesine sediment dolması veya toprak kayması gibi bir olaydan dolayı hacmin azalmış olabileceği düşünülmektedir. Bir başka neden, göletin sedimentle dolması sonucu dip savak kotunun yükseltilmesi, hacminin daha az çıkmasına neden olmuş olabilir. Karamanlı Göletinin ölçülen ve tahmin edilen değerler arasındaki farkın çok büyük olması nedeniyle bu sonuç sıra dışı değer olarakta kabul edilebilir. Karamanlı Göleti verileri olmadan yapılan regresyon analizi sonucu Şekil 9'da verilmiştir.

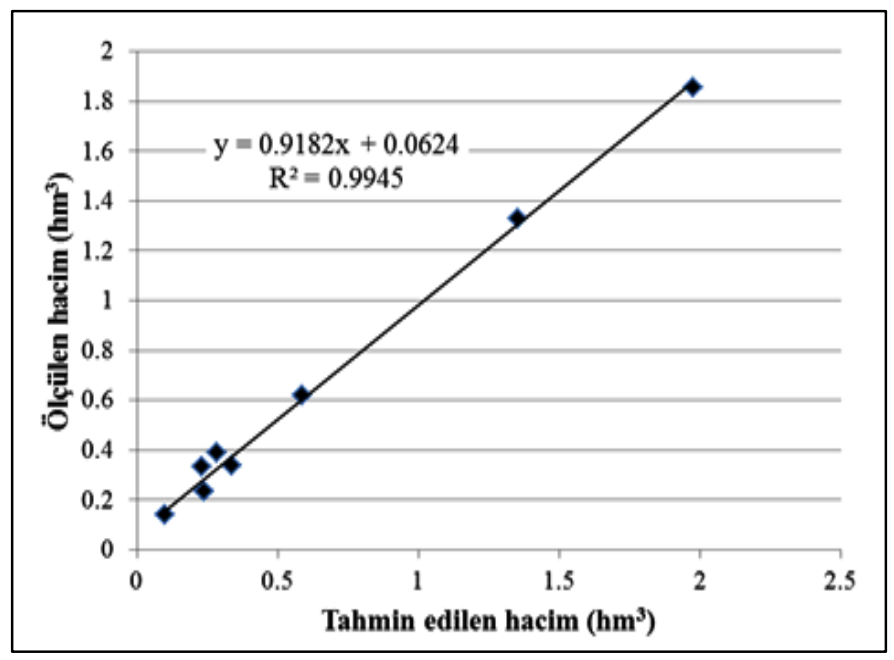

Şekil 9. Karamanlı göleti olmadan regresyon analizi sonucu

Figure 9. Result of regression anlysis without Karamanlı pond

Sonuç olarak, göletler gibi küçük su depolama yapıları özellikle kurak ve yarı kurak bölgelerde, yağışın az olduğu yaz aylarında genellikle sulama ihtiyacını karşılamak amacıyla inşaa edilen su depolama yapılarıdır. Kışın yağan yağmurları, derelerden gelen suları biriktirerek kritik dönemlerde su sağlamaları açısından önemli faydalar sağlarlar. Son yıllarda yangınlara helikopterlerle acil müdahalelerde, suyu kısa mesafeden sağlama açısından önemleri daha da artmıştır. Bu küçük su depolama yapılarının planlanmasında, gerekli bilgilerin hızlı ve doğru elde edilmesi fizibilite çalışmaları ve uygun gölet yerlerinin belirlenmesi açısından önemlidir.

Bu çalışmada, Hatay ilinde faaliyette bulunan 10 gölet için SYH ve CBS kullanılarak, hazne hacimleri tahmin edilmeye çalışılmış, tahmin sonuçlarının doğruluğu çeşitli istatistiksel yöntemlerle değerlendirilmiştir.

Yayladağı 23 Temmuz Göleti'nin ölçülen brüt depolama

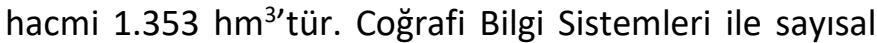


yükseklik haritasından oluşturulan sanal gölet için brüt depolama hacmi tahmini değeri ise $1.330 \mathrm{hm}^{3}$ çıkmıştır. Tahmin edilen değerin, ölçülen değere oldukça yakın olduğu görülmüştür.

Karlısu Göletinde ölçülen brüt depolama hacmi 0.589 $\mathrm{hm}^{3}$ olup, CBS ile sayısal yükseklik haritasından oluşturularak tahmin edilen hacim değeri 0.620 $\mathrm{hm}^{3 \prime}$ tür. Bu gölet içinde tahmin edilen ve ölçülen hacim değerleri arasındaki fark oldukça azdır.

Pulluyazı Göleti'nin ölçülen brüt depolama hacmi 1.975 $\mathrm{hm}^{3}$ 'tür. CBS ve sayısal yükseklik haritasından tahmin edilen gölet brüt depolama hacmi ise $1.856 \mathrm{hm}^{3}$ olarak tahmin edilmiştir. Bu göletin hacminin, diğer göletlere göre çok büyük olduğu dikkate alınırsa fark oldukça az çıkmıştır.

Dağdüzü Göleti'nin ölçülen brüt depolama hacmi ile CBS ve sayısal yükseklik haritası ile tahmin edilen gölet brüt depolama arasında sadece $400 \mathrm{~m}^{3}$ fark çıkmıştır.

Kızılçat Göleti'nin ölçülen gölet brüt depolama hacmi $0.241 \mathrm{hm}^{3}$, CBS ve sayısal yükseklik modeli oluşturularak yapılan gölet brüt depolama hacmi tahmini değeri ise $0.235 \mathrm{hm}^{3}$ olarak hesaplanmıştır. Tahmin edilen ve ölçülen hacim arasında yaklaşık $6500 \mathrm{~m}^{3}$ fark çıkmıştır. Gölet hacmine göre farkın oldukça az olduğu söylenebilir.

Yoncakaya Göleti ölçülen brüt depolama hacmi yaklaşık $0.101 \mathrm{hm}^{3}$ iken CBS ve sayısal yükseklik haritasından oluşturarak yaptığımız gölet brüt depolama hacminin tahmini değeri $0.142 \mathrm{hm}^{3}$ çıkmıştır. Tahmin değeri 40 $192 \mathrm{~m}^{3}$ fazla çıkmıştır. Yoncakaya Göleti siltasyon sebebi ile dolmuş olabileceği, ölçüm işleminin daha sonra yapılması sonucu ölçülen hazne hacminin daha az çıktığı düşünülmektedir.

Güzelyayla Göleti'nin ölçülen brüt depolama hacmi $0.283 \mathrm{hm}^{3}$, tahmin edilen gölet brüt depolama hacmi ise $0.383 \mathrm{hm}^{3}$ olarak belirlenmiştir. Güzelyayla Göleti için farkın $0.1 \mathrm{hm}^{3}$ olduğu görülmektedir. Bu farkın nedeni, bu göletin kazı-dolgu göleti olması nedeniyle, gölet yapısında yapılan değişiklikler olduğu tahmin edilmektedir.

Hisarcık Göleti'nin ölçülen brüt depolama hacmi 0.231 $\mathrm{hm}^{3}$ tür. CBS ve sayısal yükseklik haritası ile tahmin edilen gölet brüt depolama hacmi $0.332 \mathrm{hm}^{3}$ olarak hesaplanmıştır. İi değer arasında yaklaşık $100000 \mathrm{~m}^{3}$ fark olduğu görülmüştür.

Yalaz Göleti'nin brüt depolama ölçülen değeri 22058 $\mathrm{m}^{3 \prime}$ tür. CBS ve sayısal yükseklik haritası oluşturarak tahmin edilen hacim değeri ise $19082 \mathrm{~m}^{3 \prime}$ dür. Yalaz Göleti çalışma yaptığımız göletler içinde en az hacme sahip gölettir. 60 hanenin faydalandığı bu göletin tahmin edilen hacim değeri ile ölçülen değeri arasında yaklaşık $2900 \mathrm{~m}^{3}$ bir fark çıkmıştır.
Karamanlı Göleti, DSi kaynaklarından elde edilen bilgilere göre $2.110 \mathrm{hm}^{3}$ brüt depolama hacmine sahiptir. CBS ve sayısal yükseklik haritasından göletin depolama hacmi $3.857 \mathrm{hm}^{3}$ olarak tahmin edilmiştir. Çalışma yaptığımız göletlerin içinde en büyüğü Karamanlı Göleti'dir. Diğer göletler için yaptığımız CBS ile hazne hacmi belirleme çalışmaları içinde tahmin edilen değerler ve ölçülen değerler arasında en farklı çıkan gölet Karamanlı göletidir. Fark yaklaşık 1.750 hm olmuştur. 1995 yılında inşaasına başlanan gölet 2000 yılında hizmet vermeye başlamıştır. Aradan 20 yıl geçmiş olması gölet hacminin daha sonraki yıllar için tekrar hesaplanmış olabileceği diğer bir ifadeyle hacim değerinin güncelleştirilmiş olacağı tahmin edilmektedir. Göletin uzun yıllar içerisinde sediment dolması nedeniyle dip savak kotunun yükseltilmesinin de gölet hacminin daha az ölçülmesine neden olduğu düşünülmektedir. Harita verileri elde edildikten sonraki zamanlarda, gölet hacmin sediment taşınımı veya toprak kayması gibi çeşitli nedenlerle dolduğu veya Kazı-dolgu göleti olduğundan dolayı gölet inşaatı sırasında gölet haznesi doldurulup hacmi küçültülmüş olabileceği diğer düşüncelerdir. Bu gölet için ayrıca bir araştırmanın yapılması önerilmektedir.

Göletlerin projeleme ve yapım aşamaları uzun süren ve dikkat isteyen işlerdir. Bu çalışma ile CBS ve sayısal yükseklik haritası ile belirlenen bir alanda bir göletin ne kadar su toplayabileceğini potansiyel hacminin ne kadar olabileceği kısa sürede ve uzun uğraşlar gerektirmeksizin hesaplanabilmiştir. İstatiksel sonuçlara göre, Karamanlı göleti ile birlikte tüm göletler değerlendirildiğinde tahmin değerleri oldukça zayıf çıkmıştır

$\left(\mathrm{R}^{2}=0.84\right.$, Pbias $\left.=-25.08, \mathrm{RMSE}=0.55, \mathrm{NS}=0.42\right)$.

Karamanlı göleti olmadan diğer dokuz gölet için yapılan istatistiksel analizde tüm göletler için tahminlerin yeterli doğrulukta çıktığı görülmüştür $\left(R^{2}=0.99\right.$, Pbias $=-2.32$, RMSE $>0.0656$, NS $=0.98$ ).

Karamanlı göletinde tahmin edilen ve ölçülen hacimlerde ortaya çıkan büyük farkın, sonuca etkisi de büyük olmuştur. Bu farkın nedeni ayrıca araştırılmalıdır.

\section{ÖZET}

Amaç: Bu çalışmanın amacı, yapılması planlanan bir göletin su depolama hacmini, sayısal topografik haritaları kullanarak Coğrafi Bilgi Sistemleri (CBS) yardımıyla ne kadar doğru tahmin edilebileceğini araştırmaktır. $\mathrm{Bu}$ amaçla, Hatay ilinde faaliyette bulunan 10 göletin depolama hacimleri, sanal göletler oluşturularak tahmin edilmiş ve tahmin edilen değerler göletlerin gerçek hacim değerleri ile kıyaslanmıştır. 
Yöntem ve Bulgular: Gölet yerlerine ait sayısal yükseklik haritaları (DEM), Integrated Land and Water Information Systems (ILWIS) yazılımında kullanılarak sanal gölet gövdeleri oluşturulmuş ve göletlerin hacim hesaplamaları yapılmıştır. Her gölet için tahmin edilen ve ölçülen hacim değerleri istatistiksel yöntemlerle değerlendirilmiştir. Değerlendirme sonucunda tüm göletler için ölçülen ve tahmin edilen değerler için $\mathrm{R}^{2}=0.84$ olarak bulunmuştur. Sadece Karamanlı Göleti için tahmin edilen ve ölçülen hacim değeri önemli derecede farklı çıkmıştır. Karamanlı Göleti dışındaki 9 gölet için yapılan tahminler çok iyi sonuçlar vermiştir $\left(R^{2}=0.99\right.$, NSE $>0.75$ ve Pbias $\left.<0.25\right)$.

Genel Yorum: Bu sonuçlara göre, sayısal yükseklik haritası kullanılarak, yapılması planlanan göletlerin fizibilite çalışmaları için gerekli hazne hacimleri, çok kısa süre içinde 10 göletten dokuzunda yeterli doğrulukta tahmin edilmiştir. Karamanlı Göletinde hacim değerlerinde ortaya çıkan farklılığın nedenleri ayrıca araştırılmalıdır.

Çalışmanın Önemi ve Etkisi: Baraj ve göletler gibi su depolama yapılarının doğru ve hızlı bir şekilde planlanarak projelendirilmesi yoğun işgücü, bilgi ve tecrübe gerektirmektedir. Bu yapıların, depolayabilecekleri su miktarları, planlama ve fizibilite çalışmaları için önceden bilinmesi gereken bir parametredir. Projelenecek bir su depolama yapısının hazne hacminin, coğrafi bilgi sistemlerini kullanarak hali hazırda bulunan bir sayısal yükseklik modeli ile önceden yeterli doğrulukta tahmin edilmesi, fizibilite çalışmalarının hızlanmasına, dolayısıyla zaman kaybı ve işgücünü azaltacaktır. Bu çalışmada, sayısal yükseklik haritaları ile yapılması planlanan bir gölet için hazne hacminin ne kadar doğrulukta tahmin edilebileceği araştırılmıştır.

Anahtar Kelimeler: Gölet, CBS, hacim hesaplama, sayısal yükseklik haritası, Hatay.

\section{TEŞEKKÜR}

Bu çalışma, Hatay Mustafa Kemal Üniversitesi Fen Bilimleri Enstitüsü 645913 nolu Yüksek lisans tezinden üretilmiştir.

\section{ÇIKAR ÇATIŞMA BEYANI}

Makale yazarları aralarında herhangi bir çıkar çatışması olmadığını beyan ederler.

\section{ARAŞTIRMACILARIN KATKI ORANI BEYANI}

Yazarlar çalışmaya eşit oranda katkı sağlamış olduklarını beyan eder.

\section{KAYNAKLAR}

Chowdary VM, Ramakrishnan D, Srivastava YK (2009) Integrated water resource development plan for sustainable Management of Mayurakshi Watershed, India using remote sensing and GIS. Water Resour. Manag. 23: 1581-1602.

Cvar A (2014) GIS-based reservoir planning with limited data in developing nations: A case study of the lower Mekong River basin. PhD Thesis, Colorado State University, Dept. of Civil and Environmental Engineering, $304 \mathrm{p}$.

Gupta KK, Deelstra J, Sharma KD (1997) Estimation of water harvesting potential for a semiarid area using GIS and remote sensing. Remote Sens. Geogr. Inf. Syst. Des. Oper. Water Resour. Syst. 1: 53-62.

Gwenzi W, Nyamadzawo G (2014) Hydrological impacts of urbanization and urban roof water harvesting in water-limited catchments: a review. Environ. Process 1: 573-593.

İvem A (2011) Application of GIS to determine storage volume and surface area of reservoirs:The case study of Büyük Karacay Dam. Int. J. Nat. Eng. Sci. 5(13): 39-43.

İrvem A (2020) Pixel size effects on dam water storage capacity estimation using GIS:Case study of Buyuk Karacay Dam, Turkey. Fresenius Environ. Bull. 29 (07A/2020): 6338-6348.

Jha MK, Chowdhury A, Chowdary VM, Peiffer S (2006) Groundwater management and development by integrated remote sensing and geographic information systems: prospects and constraints. Water Resour. Manag. 21: 427-467.

Liebe J, van de Giesen N, Andreini, M (2005) Estimation of small reservoir storage capacities in a semi-arid environment: a case study in the Upper East region of Ghana. Phys. Chem. Earth. 30: 448-454.

Mialhe F, Gunnellv Y, Mering C (2008) Synoptic assessment of water resource variability in reservoirs by remotesensing: General approach and application to the runoff harvesting systems of south India, Water Resour. Res. 44: W05411.

Moriasi DN, Arnold JG, Van Liew MV, Bingner RL, Harmel RD, Veith TL (2007) Model evaluation guidelines for systematic quantification of accuracy in watershed simulations. T ASABE 50(3): 885-900.

Mwenge KJ, Taigbenu AE, Sejamoholo BBP (2009) A GISbased decision support system for rainwater harvesting (RHADESS). Phys. Chem. Earth. 34: 767775.

Nisar Ahamed TR, Gopal Rao K, Murthy JSR (2002) Automatic extraction of tank outlets in a sub- 
watershed using digital elevation models. Agric. Water. Manag. 57: 1-10.

Pistrika A (2010) Flood damage estimation based on flood simulation scenarios and a GIS platform. Eur. Water 30: 3-11.

Sawunyama T, Senzanje A, Mhizha A (2006) Estimation of small reservoir storage capacities in Limpopo River basin using geographical information systems (GIS) and remotely sensed surface areas: case of Mzingwane catchment. Phys. Chem. Earth. 31: 935943.

Taşkın M, İrvem A (2014) Yarı-kurak bölgelerde rezervuar yeri ve kapasitesinin CBS ile analizi. Tar. Bil. Ar. Der. 7(2): 53-59.

Toper AN (2020) Hatay ilindeki göletlerin hazne hacimlerinin coğrafi bilgi sistemleri ile belirlenmesi. Yüksek Lisans Tezi, Hatay Mustafa Kemal Üniversitesi, Fen Bil. Ens., Biyosistem Müh. ABD, 69 s.
Tsihrintzis VA, Hamid R, Fuentes HR (1996) Use of geographic information systems (GIS) in water resources: a review. Water Resour. Manag. 10: 251277.

Irvem A, Ozbuldu M (2019) Evaluation of satellite and reanalysis precipitation products using GIS for all basins in Turkey. Adv. Meteorol. 1-11.

Zhang S, Gao H, Naz BS (2014) Monitoring reservoir storage in South Asia from multisatellite remote sensing. Water Resour. 50: 8927-8943. 